\title{
Erratum to: Evaluation of the Particle Bonding for Aluminum Sample Produced by Spark Plasma Sintering
}

Mehmet Masum Tünçay, Lucie Nguyen, Philippe Hendrickx, and Mathieu Brochu

\section{Erratum to: J. of Materi Eng and Perform \\ DOI 10.1007/s11665-016-2275-1}

Please note that the unit which is written next to Eq 2 and 3 is incorrect $\left(\left[\mathrm{m} \mathrm{cm}^{2}\right]\right)$. The correct form is: $\left[\mathrm{m} \Omega \mathrm{cm}^{2}\right]$.

Additionally, please note that the unit for the resistivity that is reported in the texts at pages 3 and 4 is incorrect $(\Omega / \mathrm{m})$. The correct form is: $\Omega \mathrm{m}$.

The online version of the original article can be found under doi: 10.1007/s11665-016-2275-1.

Mehmet Masum Tünçay, Department of Mining and Materials Engineering, McGill University, 3610 University Street, Montreal, QC H3A 0C5, Canada; and Department of Metallurgical and Materials Engineering, Marmara University, 34722 Goztepe, Istanbul, Turkey; and Lucie Nguyen, Philippe Hendrickx, and Mathieu Brochu, Department of Mining and Materials Engineering, McGill University, 3610 University Street, Montreal, QC H3A 0C5, Canada. Contact e-mail: mathieu.brochu@mcgill.ca. 